Georgia State University

ScholarWorks @ Georgia State University

$1-1-2004$

\title{
A Citation Analysis of the Quantitative/Qualitative Methods Debate's Reflection in Sociology Research: Implications for Library Collection Development
}

\author{
Mandy J. Swygart-Hobaugh M.L.S., Ph.D. \\ Georgia State University, aswygarthobaugh@gsu.edu
}

Follow this and additional works at: https://scholarworks.gsu.edu/univ_lib_facpub

Part of the Library and Information Science Commons, and the Sociology Commons

\section{Recommended Citation}

Swygart-Hobaugh, A. J. (2004). A citation analysis of the quantitative/qualitative methods debate's reflection in sociology research: Implications for library collection development. Library Collections, Acquisitions, and Technical Services, 28, 180-95.

This Article is brought to you for free and open access by the Georgia State University Library at ScholarWorks @ Georgia State University. It has been accepted for inclusion in University Library Faculty Publications by an authorized administrator of ScholarWorks @ Georgia State University. For more information, please contact scholarworks@gsu.edu. 


\title{
A Citation Analysis of the Quantitative/Qualitative Methods Debate's Reflection in Sociology Research: Implications for Library Collection Development
}

\author{
Amanda J. Swygart-Hobaugh \\ Consulting Librarian for the Social Sciences \\ Russell D. Cole Library \\ Cornell College \\ 600 First Street West \\ Mt. Vernon, IA 52314-1098 \\ aswygart@cornellcollege.edu
}

NOTICE: This is the author's version of a work that was accepted for publication in Library Collections, Acquisitions, and Technical Services. Changes resulting from the publishing process, such as peer review, editing, corrections, structural formatting, and other quality control mechanisms may not be reflected in this document. Changes may have been made to this work since it was submitted for publication. A definitive version was subsequently published in LIBRARY COLLECTIONS, ACQUISITIONS, AND TECHNICAL SERVICES, [VOL 28, ISSUE W, (2004)] DOI

10.1016/j.lcats.2004.02.003 


\begin{abstract}
This study examines how the social sciences' debate between qualitative and quantitative methods is reflected in the citation patterns of sociology journal articles. Citation analysis revealed that quantitative articles were more likely to cite journal articles than monographs, while qualitative articles were more likely to cite monographs than journals. Quantitative articles cited other articles from their own quantitativedominated journals but virtually excluded citations to articles from qualitative journals, while qualitative articles cited articles from the quantitative-dominated journals as well as their own qualitative-specialized journals. Discussion and conclusions include this study's implications for library collection development.
\end{abstract}

\title{
INTRODUCTION
}

Over the last two decades, a methodological struggle has been waged in the social sciences between those championing "quantitative" and "qualitative" research paradigms. As Smith [1] notes,

On the one hand, there are those who argue that only through the application of quantitative measurements and methods can the social sciences ever hope to become 'real' sciences; on the other hand, there are those who claim that the subject matter of the social sciences is simply not amenable to quantification and all attempts to impose such measures and methods upon social behavior is just so much nonsense. (p. 29)

While quantitative research enthusiasts regularly critique qualitative research as

unreliable, invalid, anecdotal, and political—and thus not rigorously scientific—devotees to qualitative research frequently criticize quantitative research as atheoretical, divorced of context, and value-laden rather than value-free and neutral [2-4]. Denzin and Lincoln [2] elucidate the political nature of the qualitative/quantitative debate: 
The positive sciences... are often seen as the crowning achievements of Western civilization, and in their practices it is assumed that "truth" can transcend opinion and personal bias.... Qualitative research is seen as an assault on this tradition.... The opposition to positive science by the postpositivists... and the poststructuralists is seen, then, as an attack on reason and truth. At the same time, the positive science attack on qualitative research is regarded as an attempt to legislate one version of truth over another. (p. 4)

Although there are proponents of employing both quantitative and qualitative methods (triangulation) to explore social phenomena, some researchers stringently adhere to one or the other methodological approach [2,3,4-11]. Moreover, as Rabinowitz and Weseen [11] observe,

[T]he contempt in which postmodern sensibilities and the critique of science (and the qualitative research paradigm associated with those sensibilities and that critique) are held by many quantitative researchers is hardly a secret. Denigrated as hip revisionists or leftist academics, critics of science, especially from within the social sciences, are coming under increasingly harsh attack in public forums. (p. 621)

Thus, while varying in extent and animosity, there is an apparent rift between quantitative and qualitative researchers in the social sciences. Therefore, one might anticipate an expression of this methodological divide in social science scholarly communications. Theoretically, this quantitative/qualitative struggle might manifest itself in qualitative researchers' completely disregarding quantitative research, and vice versa, which may be reflected in citation patterns. Likewise, due to the oft-suggested profound ontological and epistemological differences between these methodological camps $[2,3,11,12]$, one might expect the overall citation structure of qualitative and quantitative researchers to differ considerably.

Therefore, via a citation analysis of sociology journal literature, this study examines the following questions:

1. Are there differences/similarities between qualitative and quantitative researchers' citation patterns by the following: Format? Language? Subject matter? Interdisciplinarity? Age of materials cited? Number of citations? 
2. Do the citation patterns of qualitative research published in quantitativedominated journals differ from research published in specialized qualitative journals?

3. Do the citation patterns of qualitative and quantitative research in the same journal differ?

Likewise, the study's implications for library collection development are discussed, drawing on previous literature regarding citation analyses as a collection development tool [13-18].

\section{LITERATURE REVIEW}

A sizable body of literature analyzes the structure of the sociological literature. Various citation analyses have examined sociology’s citation patterns by format, language, and age of cited materials. Several studies have found that monographs receive a greater proportion of citations than journal articles in the sociological literature [12-27]. Likewise, research demonstrates that English-language publications dominate the citations in the sociological literature $[19,20,22,28]$, and that authors are more likely to cite materials written in their own language [29,29]. Moreover, Broadus [19] and Baughman [22] found the majority of cited materials in the sociological literature are less than ten years old.

Also, various studies have explored the subject matter and/or interdisciplinarity of citation patterns in the sociological literature. For example, Satariano [30] reported that cross-disciplinarity of citation patterns was not supported by sociologists' self-reported readership patterns. However, several studies note that while concentrated within the discipline, citation patterns in the sociological literature reflect a degree of 
interdisciplinarity [19-22,31]. Additionally, while Peritz [32] found that methodological articles were cited more frequently than theoretical or empirical/substantive papers, Brown and Gilmartin [21] and Clemens et al. [26] report that empirical/substantive studies (versus theoretical and methodological studies) dominate the journal literature. Furthermore, research reveals a higher prevalence of quantitative analyses in journal articles than qualitative, while qualitative analyses are more likely to be employed in monographs than journal articles $[21,26,33]$.

Authorship patterns in the sociological literature have also been analyzed. According to research, single as well as multiple authorship is common in the sociological journal literature [21,34]. Likewise, while Lin and Nelson [34] found that top-ranked journals contained a greater percentage of papers authored by "top twenty" institutions when compared to lower ranked journals, Clemens et al. [26] report that a higher percentage of book authors received their degrees from "elite" private schools and that article authors were more likely to have received degrees from "nonelite" public schools. Furthermore, Cronin, Snyder, and Atkins [35] propose that the highly cited authors in the monographic literature differ from those in the journal literature-thus suggesting "two distinct populations" (p. 263) of important authors by publication genre.

Several recent studies explore gender's role in the citation patterns of the sociological literature. Various inquiries have found that women are more likely to author qualitative than quantitative publications [26], women are underrepresented as journal article authors [36], and women are more likely to publish books compared to core journal articles [37]. Moreover, women are more likely to cite women's than men's articles [36,38], and women are more likely to cite gender than nongender-focused 
articles [38]. Lastly, in proportion to their representation in the sociology researchers' population, women are undercited, and male authors are more likely to undercite women authors than are female authors [36].

The remaining analyses of the sociological literature's structure examine various bibliographic features. For example, Pierce [39] discusses the fluctuation in use of footnotes and visuals in core sociology journal articles from 1886 to 1985 as illustrations of "consensus development" in sociology's disciplinary history. Similarly, Brown and Gilmartin [21], Lin and Nelson [34] and Hargens [24] note that the relative number of citations in journal articles has increased since the discipline's inception. However, results diverge regarding publications' lack of citation in subsequent literature, with Oromaner [40] finding that a large proportion of publications receive little or no subsequent citations, while Bott and Hargens [41] report that a "substantial majority" of publications are subsequently cited (p. 147). Lastly, Cronin, McKenzie, Rubio, and Weaver-Wozniak [42] state that while acknowledgments do not correlate with citedness, they are significantly prevalent in sociology journal articles and are thus important bibliometric indicators of scholarly communication.

Thus, sociological literature has received ample analytical attention. However, while these studies have explored various facets of the discipline's scholarly communication structure, none have made distinctions between quantitative and qualitative researchers' respective citation patterns and general structure. Therefore, while proposing to analyze various previously examined aspects, this study's attention to the differences and/or similarities between quantitative and qualitative researchers' 
citation patterns and the implications for library collection development is analytically unique and will thus enhance the extant research literature.

\section{METHODS}

Articles from the following sociology journals were analyzed: American Journal of Sociology (AJS), American Sociological Review (ASR), Journal of Contemporary Ethnography (JCE), and Qualitative Sociology (QS). The ASR and the AJS are considered "elite publications" [26] within the field and are consistently ranked by impact factor as among the top five sociological journals by the Institute of Scientific Information's Journal Citation Reports, Social Sciences Edition [43-46]. JCE and QS publish exclusively qualitative studies: Due to the literature's suggesting that the ASR and $A J S$ tend to be dominated by quantitative studies versus qualitative $[21,25,26,33]$, selecting articles from the field's two specialized qualitative journals was necessary for comparative analyses.

To examine possible longitudinal changes in the general structure and citation patterns of sociological journal articles, samples were drawn from the 1990 and 2000 publication years. These publication dates were chosen due to their ready accessibility and the literature's implication that the qualitative/quantitative debate was salient in this time frame $[2,11]$

There were 274 total research articles for the selected years and titles, excluding commentary, book reviews, etc. The following general characteristics were recorded for all 274 articles: gender of primary author; type of article (empirical, methodological, or theoretical/critique); and methodology employed and/or discussed (quantitative, 
qualitative, or triangulated). An article was coded as "empirical" if it involved substantive analysis, "methodological" if it discussed and/or critiqued methodologies, and "theoretical/critique" if it discussed theoretical issues and/or critiqued other(s)' work(s). An article was coded as "quantitative" if it used tests of statistical significance (chi-square tests, regression analysis, etc.) or descriptive statistics (percentages, means/standard deviations, etc.). Articles that employed ethnography, content analysis, socio-historical analysis, in-depth interviews, etc., were coded as "qualitative." Lastly, "triangulated" articles were those that used both quantitative and qualitative methods.

Samples of 10 articles per year per journal were then drawn, for a total of 80 articles, including randomly selected quantitative articles from $A J S$ and $A S R$ and qualitative articles from $Q S$ and JCE. For each of the 80 articles, the number of citations by the following publication types were recorded: monograph; edited volume; academic journal; and an "other" category, which included non-scholarly periodicals, doctoral/master's thesis, government publication, conference papers, electronic journals, websites, and unpublished materials (e.g. manuscripts, working papers, personal communications, etc.). The number of foreign language publications was also noted. Additionally, intra- and inter-citation of the examined journals was documented.

Anticipating that research published in specialized qualitative journals might be substantively different than qualitative studies published in the field's prestigious but quantitative-dominated journals, ten qualitative articles were randomly selected from $A J S$ and ASR for both years and compared with ten articles from $Q S$ and JCE for both years. Also, $A J S$ and $A S R$ qualitative and quantitative articles were compared. 
Lastly, samples of ten articles per year per journal were drawn (once again purposively selecting quantitative articles from $A J S$ and $A S R$ ), or 80 articles, and five citations per article were randomly selected for age and subject analysis, for a total of 400 citations. The age of cited publications were aggregated in the following categories: less than five years old; five to ten years old; and more than ten years old. To determine the subject matter of the citations, the sources were found in OCLC WorldCat [47], and the corresponding Library of Congress [48] subject classification was recorded.

Where appropriate, the data were subjected to chi-square significance tests to assess the relationships of variables. Ball and Connor-Litton's [49] web chi-square calculator was used to generate the chi-square and critical values. Likewise, the strengths

of statistically significant relationships were assessed via phi or Cramer's phi measures of association derived from the generated chi-square values, which were interpreted as Pearson r.

\section{RESULTS}

Table 1 outlines some general characteristics of the 274 articles. Males dominated primary authorship for the AJS and ASR articles for both 1990 and 2000. In contrast, for both $Q S$ and $J C E$ the number of men and women primary authors for 1990 was relatively even, while women outnumbered men as primary authors in 2000 . However, the overall percentages across all four journals reflect men's domination of primary authorship, with $73 \%$ for 1990 and $62 \%$ for 2000 . While comparable statistics for circa 1990 were not accessible, the proportion of male to female primary authorship for 2000 from the four sampled journals closely approximated the American Sociological 
Association's data for faculty distribution by gender in sociology graduate departments for the 1997-1998 academic year: 68\% men and 32\% women across all ranks [50]. Thus, in contrast to previous findings [36], women were not underrepresented as authors for the sampled journals. However, as noted in previous literature [26], empirical articles dominated all the examined journals. Moreover, while the percentage of qualitative articles increased for both AJS and ASR from 1990 to 2000, these journals are still dominated by quantitative articles, as had been indicated in previous studies $[25,26]$.

Table 1: General Characteristics of Total Articles

\begin{tabular}{|c|c|c|c|c|c|c|}
\hline & \multicolumn{2}{|c|}{$\begin{array}{c}\text { GENDER, } \mathbf{1}^{\text {ST }} \\
\text { AUTHOR }^{1}\end{array}$} & \multicolumn{2}{|c|}{ TYPE OF ARTICLE ${ }^{2}$} & \multicolumn{2}{|c|}{ METHODS $^{3}$} \\
\hline & 1990 & 2000 & 1990 & 2000 & 1990 & 2000 \\
\hline$A J S$ & $\begin{array}{l}28 \mathrm{M} \\
(78 \%) \\
8 \mathrm{~F} \\
(22 \%)\end{array}$ & $\begin{array}{l}28 \mathrm{M} \\
(72 \%) \\
6 \mathrm{~F} \\
(15 \%) \\
5 \mathrm{Un} \\
\end{array}$ & $\begin{array}{l}27 \text { Emp } \\
1 \mathrm{Meth} \\
6 \mathrm{Th} / \mathrm{Cr}\end{array}$ & $\begin{array}{l}27 \text { Emp } \\
3 \text { Meth } \\
8 \mathrm{Th} / \mathrm{Cr}\end{array}$ & $\begin{array}{l}25 \text { Quant } \\
(81 \%) \\
5 \text { Qual } \\
(16 \%) \\
1 \text { Tri }\end{array}$ & $\begin{array}{l}20 \text { Quant } \\
(74 \%) \\
6 \text { Qual } \\
(22 \%) \\
1 \text { Tri }\end{array}$ \\
\hline$A S R$ & $\begin{array}{l}49 \mathrm{M} \\
(78 \%) \\
14 \mathrm{~F} \\
(22 \%)\end{array}$ & $\begin{array}{l}35 \mathrm{M} \\
(71 \%) \\
14 \mathrm{~F} \\
(29 \%)\end{array}$ & $\begin{array}{l}49 \mathrm{Emp} \\
1 \mathrm{Meth} \\
13 \mathrm{Th} / \mathrm{Cr}\end{array}$ & $\begin{array}{l}38 \mathrm{Emp} \\
3 \mathrm{Meth} \\
8 \mathrm{Th} / \mathrm{Cr}\end{array}$ & $\begin{array}{l}43 \text { Quant } \\
(84 \%) \\
7 \text { Qual } \\
(14 \%) \\
1 \text { Tri }\end{array}$ & $\begin{array}{l}31 \text { Quant } \\
(72 \%) \\
11 \text { Qual } \\
(26 \%) \\
1 \text { Tri } \\
\end{array}$ \\
\hline$Q S$ & $\begin{array}{l}9 \mathrm{M} \\
(50 \%) \\
9 \mathrm{~F} \\
(50 \%)\end{array}$ & $\begin{array}{l}6 \mathrm{M} \\
(27 \%) \\
16 \mathrm{~F} \\
(73 \%)\end{array}$ & $\begin{array}{l}13 \text { Emp } \\
5 \text { Meth }\end{array}$ & $\begin{array}{l}19 \mathrm{Emp} \\
2 \mathrm{Meth} \\
1 \mathrm{Th} / \mathrm{Cr}\end{array}$ & 18 Qual & 22 Qual \\
\hline$J C E$ & $\begin{array}{l}6 \mathrm{M} \\
(46 \%) \\
5 \mathrm{~F} \\
(39 \%) \\
2 \mathrm{Un} \\
\end{array}$ & $\begin{array}{l}9 \mathrm{M} \\
(41 \%) \\
13 \mathrm{~F} \\
(59 \%)\end{array}$ & $\begin{array}{l}12 \text { Emp } \\
1 \text { Meth }\end{array}$ & $\begin{array}{l}19 \text { Emp } \\
3 \text { Meth }\end{array}$ & 13 Qual & 22 Qual \\
\hline TOTAL & $\begin{array}{l}92 \mathrm{M} \\
(73 \%) \\
36 \mathrm{~F} \\
(28 \%)\end{array}$ & $\begin{array}{l}78 \mathrm{M} \\
(62 \%) \\
49 \mathrm{~F} \\
(39 \%) \\
\end{array}$ & & & & \\
\hline
\end{tabular}

${ }^{1} \mathrm{M}=$ male; F=female; Un=unknown. ${ }^{2}$ Emp=empirical; Meth=methodological; $\mathrm{Th} / \mathrm{Cr}=$ theoretical/critique.

${ }^{3}$ Quant=quantitative; Qual=qualitative; Tri=triangulated. 
Table 2 contains data reflecting the relationship of gender of primary authors and methodology choice. As the data for 1990 indicate, a significant interaction was found between gender and choice of method, with women more likely to author qualitative and men more likely to author quantitative research (chi-square $(1)=8.04, p<.01$ ), which echoes a previous finding that women are more likely to author qualitative than quantitative publications [26]. However, a phi of $0.27\left(\mathrm{r}^{2}=0.0729\right)$ indicates that only $7.3 \%$ of method choice is explained by gender, indicating other variables account for 92.7\% of method choice. Additionally, while women were slightly more likely to author qualitative and men more likely to author quantitative research in the 2000 sample, this relationship was not statistically significant (chi-square $(1)=3.05, \mathrm{p}<.05$ ).

Table 2: Observed and Expected Distribution of Methodologies by Gender

\begin{tabular}{||l|l|l|l|l||}
\hline & & QUANTITATIVE & QUALITATIVE & \multicolumn{1}{||}{ TOTAL } \\
\hline \multirow{3}{*}{1990} & Male & $54(47.4)$ & $22(28.6)$ & $\mathbf{7 6}$ \\
\cline { 2 - 5 } & Female & $14(20.6)$ & $19(12.4)$ & $\mathbf{3 3}$ \\
\cline { 2 - 5 } & TOTAL & $\mathbf{6 8}$ & $\mathbf{4 1}$ & $\mathbf{1 0 9}$ \\
\hline \multirow{3}{*}{2000} & Male & $31(26.6)$ & $30(34.5)$ & $\mathbf{6 1}$ \\
\cline { 2 - 5 } & Female & $16(20.5)$ & $31(26.6)$ & $\mathbf{4 7}$ \\
\cline { 2 - 5 } & TOTAL & $\mathbf{4 7}$ & $\mathbf{6 1}$ & $\mathbf{1 0 8}$ \\
\hline
\end{tabular}

Note: Numbers in parentheses are expected distributions if no relationship existed between the variables.

Table 3 contains data comparing the total citations by format for the quantitative articles sampled from $A J S$ and $A S R$ and the qualitative articles sampled from $Q S$ and $J C E$ for 1990 and 2000. A statistically significant relationship was found between methodology and cited formats for both 1990 (chi-square $(9)=122.53, \mathrm{p}<.001)$ and 2000 (chi-square $(9)=99.03, \mathrm{p}<.001)$. However, a Cramer's phi of $0.16\left(\mathrm{r}^{2}=0.0256\right)$ for 1990 and $0.12\left(r^{2}=0.0144\right)$ for 2000 indicates that other variables remain undetected that explain choice of cited formats. 
The most marked distinction deserving discussion was the disparity by methodologies for citing monographs versus journals. For 1990, both quantitative AJS and $A S R$ were less likely while qualitative $Q S$ and $J C E$ were comparably more likely to cite monographs. Likewise, for 1990, while the observed citations to journals for AJS closely approximated the expected values if no relationship existed, the sampled ASR articles were comparatively more likely to cite journals than were the $Q S$ and $J C E$ articles. Moreover, for 2000, both AJS and ASR were comparably less likely to cite monographs and more likely to cite journals, while the opposite was demonstrated for the $Q S$ and $J C E$ articles, which were comparably more likely to cite monographs and less likely to cite journals. Therefore, the data indicate that overall for both years the quantitative researchers showed a propensity for citing journals versus monographs, while the qualitative researchers demonstrated a tendency for citing monographs versus journals.

Lastly, as delineated in Table 3, the total number of citations differed between the four journals and changed between the examined years. The sampled AJS articles had the most total citations, with 594 for 1990 and 710 for 2000 - a $20 \%$ increase. The ASR sample increased its total number of citations from 395 in 1990 to 573 in 2000, a 45\% increase. The sampled JCE articles demonstrated the most evident increase of total citations between the two years, with 280 for 1990 and 522 for 2000 - an $86 \%$ increase. In contrast, the $Q S$ sample slightly decreased its total number of citations from 363 in 1990 to 328 in 2000 - a $10 \%$ decrease. 
Table 3: Observed and Expected Citations by Format, $A J S$ and $A S R$ Quantitative and $Q S$ and $J C E$ Qualitative Articles

\begin{tabular}{||l|l|l|l|l|l|l||}
\hline & & MONOGRAPH & $\begin{array}{c}\text { EDITED } \\
\text { VOLUME }\end{array}$ & JOURNAL & OTHER & TOTAL \\
\hline \multirow{4}{*}{$\mathbf{1 9 9 0}$} & $\boldsymbol{A J S}$ & $188(213.3)$ & $91(83.4)$ & $254(255.1)$ & $61(42.2)$ & $\mathbf{5 9 4}$ \\
\cline { 2 - 7 } & $\boldsymbol{A S R}$ & $97(141.8)$ & $34(55.4)$ & $241(169.7)$ & $23(28.1)$ & $\mathbf{3 9 5}$ \\
\cline { 2 - 7 } & $\boldsymbol{Q S}$ & $190(130.3)$ & $51(50.9)$ & $105(155.9)$ & $17(25.8)$ & $\mathbf{3 6 3}$ \\
\cline { 2 - 7 } & $\boldsymbol{J C E}$ & $111(100.5)$ & $53(39.3)$ & $101(120.3)$ & $15(19.9)$ & $\mathbf{2 8 0}$ \\
\cline { 2 - 7 } & TOTAL & $\mathbf{5 8 6}$ & $\mathbf{2 2 9}$ & $\mathbf{7 0 1}$ & $\mathbf{1 1 6}$ & $\mathbf{1 6 3 2}$ \\
\hline \multirow{4}{*}{$\mathbf{2 0 0 0}$} & $\boldsymbol{A J S}$ & $239(266.6)$ & $84(94.5)$ & $333(286.6)$ & $54(62.3)$ & $\mathbf{7 1 0}$ \\
\cline { 2 - 7 } & $\boldsymbol{A S R}$ & $173(215.2)$ & $69(76.3)$ & $281(231.3)$ & $50(50.3)$ & $\mathbf{5 7 3}$ \\
\cline { 2 - 7 } & $\boldsymbol{Q S}$ & $168(123.2)$ & $37(43.7)$ & $80(132.4)$ & $43(28.8)$ & $\mathbf{3 2 8}$ \\
\cline { 2 - 7 } & $\boldsymbol{J C E}$ & $221(196.0)$ & $94(69.5)$ & $167(210.7)$ & $40(45.8)$ & $\mathbf{5 2 2}$ \\
\cline { 2 - 7 } & TOTAL & $\mathbf{8 0 1}$ & $\mathbf{2 8 4}$ & $\mathbf{8 6 1}$ & $\mathbf{1 8 7}$ & $\mathbf{2 1 3 3}$ \\
\hline
\end{tabular}

Table 4 contains data for comparison of qualitative articles sampled from AJS and $A S R$ and from $Q S$ and JCE for 1990 and 2000. Statistically significant relationships were found for both 1990 (chi-square $(9)=51.65, \mathrm{p}<.001)$ and $2000($ chi-square $(9)=109.15$, $\mathrm{p}<.001$ ), but the nature of the relationships varied across the sampled journals and years. For example, for 1990 the sampled AJS and JCE articles were less likely to cite and ASR and $Q S$ more likely to cite monographs. However, for the 2000 samples, the AJS and $Q S$ articles were more likely to cite monographs, while the ASR and JCE articles were less likely to cite this publication format. Likewise, the AJS and ASR articles were less likely and the $Q S$ and JCE articles were more likely to cite journals in the 1990 samples. However, for the 2000 samples the $A S R$ articles were more likely to cite journals, the sampled $Q S$ articles cited journals the expected number of times if no significant relationship existed, the $A J S$ articles were less likely to cite journals, and the $J C E$ articles were more likely to cite journals. Nevertheless, a Cramer's phi of $0.12\left(r^{2}=0.0144\right)$ for 
1990 and $0.16\left(r^{2}=0.0256\right)$ for 2000 indicates that other variables remain undetected that explain choice of cited formats.

Lastly, Table 4 also delineates the pattern differences for total number of citations for the qualitative samples. The AJS articles had the most total citations and showed the most evident increase of the four journals, with 430 for 1990 and 709 for 2000 —a $65 \%$ increase. The ASR sample total number of citations from 1990 to 2000 remained relatively stable, with 392 for 1990 and 385 for 2000 - a $1.7 \%$ decrease. The JCE articles demonstrated a dramatic increase of total citations between the two years, with 112 for 1990 and 264 for 2000 — a $136 \%$ increase. In contrast, the QS sample slightly decreased its total number of citations from 180 in 1990 to 136 in 2000 - a $24.4 \%$ decrease.

Table 4: Observed and Expected Citations by Format, AJS and ASR Qualitative and $Q S$ and JCE Qualitative Articles

\begin{tabular}{||l|l|l|l|l|l|l||}
\hline & & MONOGRAPH & $\begin{array}{c}\text { EDITED } \\
\text { VOLUME }\end{array}$ & JOURNAL & OTHER & TOTAL \\
\hline \multirow{5}{*}{$\mathbf{1 9 9 0}$} & $\boldsymbol{A J S}$ & $204(206.9)$ & $72(57.9)$ & $104(112.3)$ & $50(52.9)$ & $\mathbf{4 3 0}$ \\
\cline { 2 - 7 } & $\boldsymbol{A S R}$ & $195(188.6)$ & $40(52.8)$ & $86(102.4)$ & $71(48.2)$ & $\mathbf{3 9 2}$ \\
\cline { 2 - 7 } & $\boldsymbol{Q S}$ & $95(86.6)$ & $26(24.3)$ & $51(47.0)$ & $8(22.1)$ & $\mathbf{1 8 0}$ \\
\cline { 2 - 7 } & $\boldsymbol{J C E}$ & $42(53.9)$ & $12(15.1)$ & $50(29.3)$ & $8(13.8)$ & $\mathbf{1 1 2}$ \\
\cline { 2 - 7 } & TOTAL & $\mathbf{5 3 6}$ & $\mathbf{1 5 0}$ & $\mathbf{2 9 1}$ & $\mathbf{1 3 7}$ & $\mathbf{1 1 4}$ \\
\hline \multirow{4}{*}{$\mathbf{2 0 0 0}$} & $\boldsymbol{A J S}$ & $369(332.7)$ & $146(112.0)$ & $169(201.2)$ & $25(63.1)$ & $\mathbf{7 0 9}$ \\
\cline { 2 - 7 } & $\boldsymbol{A S R}$ & $172(180.7)$ & $34(60.8)$ & $114(109.3)$ & $65(34.3)$ & $\mathbf{3 8 5}$ \\
\cline { 2 - 7 } & $\boldsymbol{Q S}$ & $70(63.8)$ & $19(21.5)$ & $38(38.6)$ & $9(12.1)$ & $\mathbf{1 3 6}$ \\
\cline { 2 - 7 } & $\boldsymbol{J C E}$ & $90(123.9)$ & $37(41.7)$ & $103(74.9)$ & $34(23.5)$ & $\mathbf{2 6 4}$ \\
\cline { 2 - 7 } & $\mathbf{T O T A L}$ & $\mathbf{7 0 1}$ & $\mathbf{2 3 6}$ & $\mathbf{4 2 4}$ & $\mathbf{1 3 3}$ & $\mathbf{1 4 9 4}$ \\
\hline
\end{tabular}

Table 5 contains data comparing the quantitative and qualitative articles sampled from $A J S$ and $A S R$. A statistically significant relationship was found between methodology and cited formats for both 1990 (chi-square $(9)=182.53, \mathrm{p}<.001)$ and 2000 (chi-square $(9)=170.61, \mathrm{p}<.001)$. Likewise, a consistent pattern emerged across 
journal titles and years: the quantitative articles were comparatively less likely to cite monographs and more likely to cite journals, and the qualitative articles were comparatively more likely to cite monographs and less likely to cite journals. However, a Cramer's phi of $0.18\left(r^{2}=0.0324\right)$ for 1990 and $0.16\left(r^{2}=0.0256\right)$ for 2000 indicates that other variables remain undetected that explain choice of cited formats.

Table 5: Observed and Expected Citations by Format, $A J S$ and $A S R$, Quantitative and Qualitative Articles

\begin{tabular}{|c|c|c|c|c|c|c|c|}
\hline & & & MONOGRAPH & $\begin{array}{c}\text { EDITED } \\
\text { VOLUME }\end{array}$ & JOURNAL & OTHER & TOTAL \\
\hline \multirow{5}{*}{1990} & \multirow[b]{2}{*}{$A J S$} & Quant & $188(223.0)$ & $91(78.7)$ & $254(227.3)$ & $61(61.1)$ & 594 \\
\hline & & Qual & 204 (164.3) & $72(569)$ & 104 (164.6) & $50(44.2)$ & 430 \\
\hline & \multirow[b]{2}{*}{$A S R$} & Quant & $97(151.0)$ & $34(52.3)$ & $241(151.2)$ & $23(40.6)$ & 395 \\
\hline & & Qual & $195(141.8)$ & $40(49.1)$ & $86(142.0)$ & $50(38.1)$ & 371 \\
\hline & \multicolumn{2}{|c|}{ TOTAL } & 684 & 237 & 685 & 184 & 1790 \\
\hline \multirow{5}{*}{2000} & \multirow[b]{2}{*}{$A J S$} & Quant & $239(289.5)$ & $84(101.2)$ & $333(272.5)$ & $54(46.8)$ & 710 \\
\hline & & Qual & $369(289.1)$ & $146(101)$ & $169(272.1)$ & $25(46.7)$ & 709 \\
\hline & \multirow[b]{2}{*}{$A S R$} & Quant & $173(233.7)$ & $69(81.7)$ & 281 (219.9) & $50(37.8)$ & 573 \\
\hline & & Qual & $172(140.7)$ & $34(49.2)$ & $114(132.4)$ & $25(22.7)$ & 345 \\
\hline & \multicolumn{2}{|c|}{ TOTAL } & 953 & 333 & 897 & 154 & 2337 \\
\hline
\end{tabular}

Table 6 shows the number and percentages of citations made to articles published in the same journal title and in the other examined journals. As the data indicates, neither of the quantitative $A J S$ or $A S R$ samples cited $Q S$ or $J C E$ for either 1990 or 2000, while only one of the qualitative $A S R$ articles cited $Q S$, and only once. However, both the quantitative and qualitative $A J S$ and $A S R$ articles cited other $A J S$ articles as well as $A S R$ articles, with these citations accounting for varying percentages of journal citations. In contrast, the $Q S$ and $J C E$ articles cited other $Q S$ and $J C E$ articles as well as $A J S$ and $A S R$ articles, with varying percentages of the citations to these particular titles. 
Table 6: Citations to AJS, ASR, QS, and JCE

\begin{tabular}{|c|c|c|c|c|c|c|c|c|c|}
\hline & & \multicolumn{2}{|c|}{$A J S$} & \multicolumn{2}{|c|}{$A S R$} & \multicolumn{2}{|c|}{$Q S$} & \multicolumn{2}{|c|}{$J C E$} \\
\hline & & 1990 & 2000 & 1990 & 2000 & 1990 & 2000 & 1990 & 2000 \\
\hline \multirow[t]{2}{*}{ Quant } & $\begin{array}{r}\boldsymbol{A J S} \\
\text { Total: } \\
\%^{1}:\end{array}$ & $\begin{array}{l}40 \\
16 \%\end{array}$ & $\begin{array}{l}58 \\
\mathbf{1 7 \%} \\
\end{array}$ & $\begin{array}{l}40 \\
16 \%\end{array}$ & $\begin{array}{l}55 \\
17 \%\end{array}$ & $\begin{array}{l}0 \\
---\end{array}$ & $\begin{array}{l}0 \\
---\end{array}$ & $\begin{array}{l}0 \\
---\end{array}$ & $\begin{array}{l}0 \\
---\end{array}$ \\
\hline & $\begin{array}{r}\boldsymbol{A S R} \\
\text { Total: } \\
\%:\end{array}$ & $\begin{array}{l}21 \\
9 \%\end{array}$ & $\begin{array}{l}19 \\
7 \%\end{array}$ & $\begin{array}{l}78 \\
\mathbf{3 2 \%}\end{array}$ & $\begin{array}{l}30 \\
11 \%\end{array}$ & $\begin{array}{l}0 \\
---\end{array}$ & $\begin{array}{l}0 \\
---\end{array}$ & $\begin{array}{l}0 \\
---\end{array}$ & $\begin{array}{l}0 \\
---\end{array}$ \\
\hline \multirow{4}{*}{ Qual } & $\begin{array}{r}\boldsymbol{A J S} \\
\text { Total: } \\
\%:\end{array}$ & $\begin{array}{l}7 \\
7 \%\end{array}$ & $\begin{array}{l}15 \\
9 \%\end{array}$ & $\begin{array}{l}13 \\
12.5 \\
\%\end{array}$ & $\begin{array}{l}31 \\
18 \%\end{array}$ & $\begin{array}{l}0 \\
---\end{array}$ & $\begin{array}{l}0 \\
---\end{array}$ & $\begin{array}{l}0 \\
---\end{array}$ & $\begin{array}{l}0 \\
---\end{array}$ \\
\hline & \begin{tabular}{r}
\multicolumn{1}{|c|}{$\boldsymbol{S S R}$} \\
Total: \\
$\%:$
\end{tabular} & $\begin{array}{l}9 \\
11 \% \\
\end{array}$ & $\begin{array}{l}24 \\
21 \% \\
\end{array}$ & $\begin{array}{l}12 \\
14 \% \\
\end{array}$ & $\begin{array}{l}15 \\
13 \% \\
\end{array}$ & $\begin{array}{l}0 \\
--- \\
\end{array}$ & $\begin{array}{l}1 \\
1 \%\end{array}$ & $\begin{array}{l}0 \\
--- \\
\end{array}$ & $\begin{array}{l}0 \\
--- \\
\end{array}$ \\
\hline & $\begin{array}{r}\boldsymbol{Q S} \\
\text { Total: } \\
\%:\end{array}$ & $\begin{array}{l}2 \\
2 \%\end{array}$ & $\begin{array}{l}4 \\
5 \%\end{array}$ & $\begin{array}{l}12 \\
11 \%\end{array}$ & $\begin{array}{l}2 \\
3 \%\end{array}$ & $\begin{array}{l}6 \\
6 \%\end{array}$ & $\begin{array}{l}2 \\
3 \%\end{array}$ & $\begin{array}{l}4 \\
4 \%\end{array}$ & $1 \%$ \\
\hline & $\begin{array}{r}\boldsymbol{J C E} \\
\text { Total: } \\
\%:\end{array}$ & $\begin{array}{l}10 \\
10 \%\end{array}$ & $\begin{array}{l}11 \\
\mathbf{7 \%}\end{array}$ & $\begin{array}{l}10 \\
10 \%\end{array}$ & $\begin{array}{l}10 \\
6 \%\end{array}$ & $1 \%$ & $\begin{array}{l}3 \\
2 \%\end{array}$ & $\begin{array}{l}10 \\
10 \%\end{array}$ & $\begin{array}{l}4 \\
2 \%\end{array}$ \\
\hline
\end{tabular}

${ }^{1}$ Percentage of total journal citations.

Table 7 contains data regarding the age and subject matter of the cited publications for the sample of 400 citations. Across all four journals for both years (excepting $A S R$ for 2000), the largest percentage of citations was to sources more than ten years old. Of the four titles, JCE had the highest percentage of citations that were more than ten years old, with $66 \%$ for 1990 and $64 \%$ for 2000 , while ASR had only $24 \%$ for the year 2000. The remaining age of cited materials varied between titles, with AJS showing roughly an even split of $30 \%$ for five to ten year-old and $30 \%$ for less than five year-old publications. The ASR citations varied more considerably between years, with an increase of five to ten year-old citations from $34 \%$ in 1990 to $44 \%$ in 2000 and a nearly doubled percentage of less than five year-old citations from $16 \%$ in 1990 to $30 \%$ in 2000 . 
While $Q S$ 's less than five year-old citations remained relatively stable at $24-28 \%$ for both years, the percentage of citations to materials five to ten years old increased by $14 \%$ from 1990 to 2000. Lastly, JCE's percentage of citations to five to ten year-old materials decreased from $32 \%$ in 1990 to $22 \%$ in 2000 , while its less than five year-old citations increased $12 \%$ from $2 \%$ to $14 \%$ for the respective years.

Also, the majority of citations were to social science $(\mathrm{H})$ publications, with sociology (HM) dominating the cited materials, ranging from $20-44 \%$ of the examined citations. Overall, the AJS and ASR samples had higher percentages of citations to statistics (HA), economic theory (HB), and industry/labor-related materials (HD) than the $Q S$ or JCE samples, while the latter had higher percentages of citations to family/women's studies (HQ) materials than the former. Welfare/criminology (HV) materials were also cited, with the JCE 1990 sample showing the highest percentage for this subject area.

In contrast, while comparably small percentages were to subjects outside of the social sciences $(\mathrm{H})$, the sampled citations represented a wide range of disciplines, including psychology $(\mathrm{BF})$, religion $(\mathrm{BL})$, history $(\mathrm{D})$, Indiana tribes and cultures $(\mathrm{E})$, anthropology (GN), political science (J), law (K), education (L), language and literature (P), science (Q), and medicine (R). The QS 1990 and JCE 2000 samples had comparably higher percentages of citations to psychology (BF) materials. Also, the ASR 2000, QS, and JCE 2000 samples had higher percentages of citations to medicine-related (R) materials than the AJS sample. Lastly, while the 2000 ASR sample had a comparably high percentage of citations to education (L) materials, the majority of these citations was from one article in the sample and thus reflects skewed results. 
Table 7: Age and Subject Matter of Citations

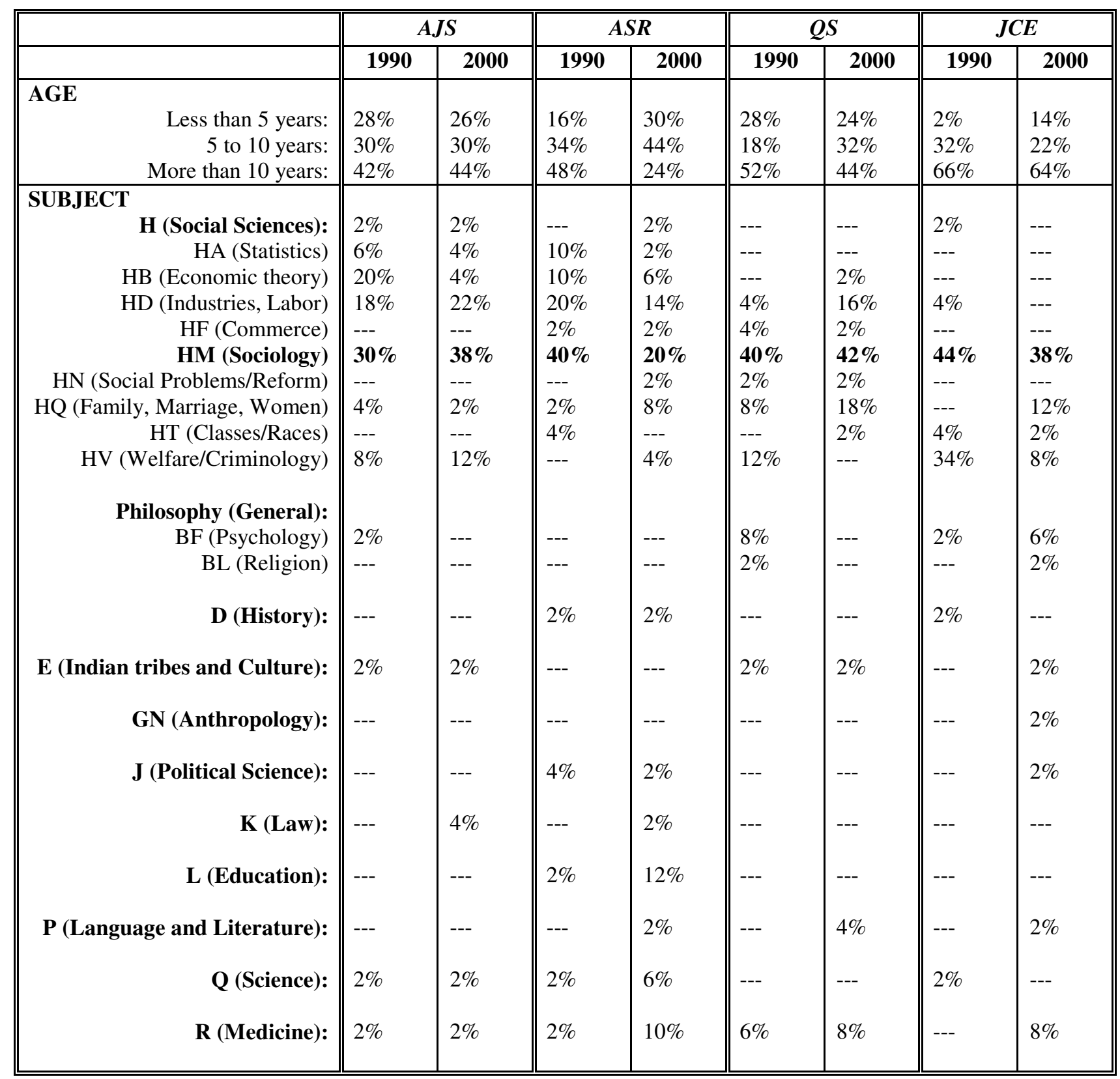

\section{DISCUSSION and CONCLUSIONS}

The findings support a selection of the previous studies on sociology research's citation patterns and overall structure. Empirical articles dominated all the examined journals, which is noted in preceding literature [26]. Moreover, both $A J S$ and $A S R$ were 
dominated by quantitative articles, as had been indicated in previous studies [25,26].

Additionally, as reported in earlier research, English-language publications dominated the citations in the examined journals [19,20,22,29]. Similarly, while citations were concentrated within the social sciences and particularly in the sociological discipline, a degree of interdisciplinary referencing was reflected [19-22,31]. Lastly, as Hargens [24] also reported, the relative number of citations in journal articles increased between 1990 and 2000, with $A J S$ and $A S R$ articles having comparably more citations than the $Q S$ and $J C E$ articles.

However, some of the findings do not support preceding studies. In contrast to previous research [36], women were not underrepresented as authors in the four journals. Moreover, while Broadus [19,20] and Baughman [22] found the majority of cited materials in the sociological literature were less than ten years old, this study indicates that the majority of citations were more than ten years old. Likewise, while previous research found that monographs received a greater proportion of citations than journal articles in the sociological literature [19-27], this study indicates that this phenomenon varies by methodology. Perhaps the most insightful finding of this research, the sampled qualitative articles were comparably more likely to cite monographs than journal articles, while quantitative articles were more likely to cite journals than monographs. While this interpretation is purely speculative at this point, that the qualitative articles were more likely to reference monographs than journal articles may indicate their increased likelihood of referencing qualitative research, as previous studies indicate that qualitative analyses are more likely to be employed in monographs than journal articles $[21,26,33]$. 
The findings in Table 6 also warrant discussion. The inter- and intra-citation of these journals was documented to begin exploring the question as to whether quantitative researchers cite qualitative researchers, and vice versa. As AJS and ASR are quantitativedominated journals, there is a high likelihood that a citation to an article in these journals is to one using quantitative research. And, as the data shows, the quantitative articles from $A J S$ and $A S R$ cited other articles from $A J S$ and $A S R$, while-except for one citation-excluded citations to $Q S$ or JCE articles. In contrast, $Q S$ and JCE cited articles from the quantitative-dominated $A J S$ and $A S R$ as well as from $Q S$ or $J C E$. Thus, a liberal and at this point speculative interpretation of these findings is that quantitative researchers are more likely to cite quantitative research, while qualitative researchers may not be as exclusive. Although the data of this study cannot provide definitive support for this proposition, it does point to a possible relationship and thus warrants further research.

Moreover, the findings have various implications for library collection development for the sociology discipline. While collection development choices should be primarily guided by localized knowledge of the particular institution's research needs, citation analyses of the broader discipline can inform library collection development, as noted in previous literature [13-18]. This study suggests several consequences for library collection development for sociological research, including selection, storage, and weeding of materials as well as serials/monograph budget allocation.

For example, foreign-language materials do not appear to be in extreme demand for sociological researchers, as they were seldom cited. Thus, reducing or ceasing collecting in this area may be warranted. Additionally, foreign-language materials might 
be moved to storage — or perhaps weeded from the collection altogether-if their ready accessibility is not crucial.

Likewise, that the majority of citations were to materials more than ten years old has consequences for library collection development. This finding indicates that older materials are relevant to sociological research and thus should remain readily accessible. Consequently, decisions about moving older materials to storage or weeding them from the collection should be tempered by the knowledge of their importance to sociologists' research needs.

Additionally, the interdisciplinarity of citation patterns in sociological research has implications for library collection development. This finding reveals that collecting across disciplines is necessary to meet sociologists' research needs. Thus, librarians selecting for sociology should also be aware of materials in other disciplines that are relevant to the sociology faculty's research. Likewise, when making storage or weeding decisions for disciplines other than sociology, librarians must consider the repercussions for the sociologists at their institution.

Furthermore, the methodological preferences of the sociologists may have consequences for library collection development. Specifically, the findings indicate a methodological disparity in citations to monographs and journals, with qualitative researchers being more likely to reference the former and quantitative the latter. Therefore, when developing collections for sociological researchers, those responsible should be aware of the researchers' methodological preferences and how that in turn may influence their format preferences: if the researchers predominantly use quantitative methods, they may be more interested in journals versus monographs, and vice versa. 
Likewise, that researchers may have a partiality to materials that employ particular methodologies should also inform selection decisions: if the researchers primarily use qualitative methods, they may prefer qualitative works to quantitative, and vice versa. Thus, these preferences may inform materials selection. Correspondingly, methodological preferences might be considered when determining serials/monographs budget allocation: if qualitative researchers dominate the sociology department, perhaps more money should be allocated to the monograph budget, and vice versa.

Before concluding, limitations of this research study must be acknowledged. Analyzing qualitative articles rather than monographs is one such limitation. As qualitative analyses are more likely to be developed in monographs rather than journals [26] and research has shown citation patterns of sociology monographs differ from journal article's citation patterns [35], limiting analyses to qualitative journal articles may not reflect the overall citation structures of qualitative research in sociology. Thus, future research should examine the qualitative/quantitative distinction in the monographic literature to explore whether similar differences in citation patterns arise. Additionally, while several statistically significant relationships were found within the data, the strength of the association between the variables (as measured by phi or Cramer's phi) in all cases were found to be minimal, thus indicating that other pertinent factors were not explained. Consequently, further research is needed to explore other variables that may contribute to the observed phenomenon.

In conclusion, this study gives preliminary support to the initial suppositions of differences between quantitative and qualitative sociologists' citation patterns; further research is needed to examine the extent and nature of these differences within the 
sociology discipline as well as the other social sciences. Nevertheless, the findings warrant consideration in library collection development decisions. Librarians' localized knowledge of their particular institution's research needs should always chiefly guide collection development choices. However, this study indicates that librarians should also bear in mind the discipline's overall citation patterns as well as the influence of methodology on scholarly resource preferences when making decisions regarding their collections.

\section{ACKNOWLEDGMENTS}

The author wishes to acknowledge Dr. Thomas Nisonger, professor in the Indiana University School of Library and Information Science, for his useful advice and continuous support for this study, and Dr. J. William Spencer, professor in the Purdue University Department of Sociology and Anthropology, for sparking the author's interest in sociology's methodological debates.

\section{REFERENCES}

1. Smith, C. W. (1989). The qualitative significance of quantitative representation. In B. Glassner \& J. D. Moreno (Eds.), The qualitative-quantitative distinction in the social sciences (pp. 29-42). Boston, MA: Kluwer Academic Publishers.

2. Denzin, N. K., \& Lincoln, Y. S. (1994). Introduction: entering the field of qualitative research. In N. K. Denzin, \& Y. S. Lincoln (Eds.), Handbook of qualitative research, 1st ed., (pp. 1-17). Thousand Oaks, CA: Sage Publications. 
3. Silverman, D. (1998). Qualitative/quantitative. In C. Jenks (Ed.), Core sociological dichotomies (pp. 78-95). Thousand Oaks, CA: Sage Publications.

4. Schmuttermaier, J. R., \& Schmitt, D. (2001). Smoke and mirrors: modernist illusions in the quantitative versus qualitative research debate. Sociological Research Online, 6 (2). Retrieved May 7, 2003 from http://www.socresonline.org.uk/.

5. Kidder, L. H., \& Fine, M. (1997). Qualitative inquiry in psychology: a radical tradition. In D. R. Fox \& I. Prilleltensky (Eds.), Critical psychology: an introduction (pp. 34-50). Thousand Oaks, CA: Sage Publications.

6. Jayaratne, T. E., \& Stewart, A. J. (1991). Quantitative and qualitative methods in the social sciences: current feminist issues and practical strategies. In M. M. Fonow \& J. A. Cook (Eds.), Beyond methodology: feminist scholarship as lived research (pp. 85-106). Bloomington, IN: Indiana University Press.

7. Keller, E. F. (1985). Reflections on gender and science. New Haven, CT: Yale University Press.

8. Krantz, D. L. (1995). The dynamics of controversy: the quantitative-qualitative debate. Evaluation and Program Planning, 18 (1), 89-96.

9. Sechrest, L., \& Sidani, S. (1995). Quantitative and qualitative methods: is there an alternative? Evaluation and Program Planning, 18 (1), 77-87.

10. Shadish, W. R. (1995). The quantitative-qualitative debates: 'deKuhnifying' the conceptual context. Evaluation and Program Planning, 18 (1), 47-49. 
11. Rabinowitz, V. C., \& Weseen, S. (1997). Elu(ci)d(at)ing epistemological impasses: re-viewing the qualitative/quantitative debates in psychology. Journal of Social Issues, 53 (4), 605-630.

12. Sale, J. E. M., Lohfeld, L. H., \& Brazil, K. (2002). Revisiting the quantitativequalititative debate: implications for mixed-methods research. Quality and Quantity, 36 (1), 43-53.

13. Bowman, M. (1991). Format citation patterns and their implications for collection development in research libraries. Collection Building, 11 (1), 2-8.

14. Burdick, A. J., Butler, A. \& Sullivan, M. G. (1993). Citation patterns in the health sciences: implications for serials/monographic fund allocation. Bulletin of the Medical Library Association, 81 (1), 44-47.

15. Buchanan, A. L., \& Herubel, J. P. V. M. (1994). Profiling PhD dissertation bibliographies: serials and collection development in political science. Behavioral and Social Sciences Librarian, 13 (1), 1-10.

16. Edwards, S. (1999). Citation analysis as a collection development tool: a bibliometric study of polymer science theses and dissertations. Serials Review, 25 (1), 11-20.

17. Gooden, A. M. (2001). Citation analysis of chemistry doctoral dissertations: an Ohio State University case study. Issues in Science and Technology Librarianship, 32. Retrieved May 7, 2003 from http://www.istl.org/istl/01fall/refereed.html. 
18. Ching, J. T. Y., \& Chennupati, K. R. (2002). Collection evaluation through citation analysis techniques: a case study of the Ministry of Education, Singapore. Library Review, 51 (8/9), 398-405.

19. Broadus, R. N. (1952) An analysis of literature cited in the American Sociological Review. American Sociological Review, 17 (3), 355-357.

20. Broadus, R. N. (1967). A citation study for sociology. American Sociologist, 2 (1), 19-20.

21. Brown, J. S., \& Gilmartin, B. C. (1969). Sociology today: lacunae, emphases, and surfeits. American Sociologist, 4 (4), 283-291.

22. Baughman, J. C. (1974). A structural analysis of the literature of sociology. Library Quarterly, 44 (4), 293-308.

23. Line, M. B. (1981). The structure of social science literature as shown by a largescale citation analysis. Social Science Information Studies, 1 (1), 67-87.

24. Hargens, L. L. (1991). Impressions and misimpressions about sociology journals. Contemporary Sociology, 20 (3), 343-349.

25. Sullivan, T. A. (1994). Genre in sociology: the case for the monograph. In R. J. Simon \& J. J. Frye (Eds.), Editors as gate keepers: getting published in the social sciences (pp. 159-175). Lanham, MD: Rowman \& Littlefield Publishers.

26. Clemens, E. S., Powell, W. W., Mcllwaine, K., \& Okamoto, D. (1995). Centennial essay: careers in print: books, journals, and scholarly reputation. American Journal of Sociology, 101 (2), 433-494. 
27. Lindholm-Romantschuk, Y. \& Warner, J. (1996). The role of monographs in scholarly communication: an empirical study of philosophy, sociology, and economics. Journal of Documentation, 52 (4), 389-404.

28. Yitzhaki, M. (1998). The 'language preference' in sociology: measures of 'language self-citation', 'relative own-language preference indicator', and 'mutual use of languages'. Scientometrics, 41 (1/2), 243-254.

29. Egghe, L., Rousseau, R., \& Yitzhaki, M. (1999). The 'own-language preference': measures of relative language self-citation. Scientometrics, 45 (2), 217-232.

30. Satariano, W. A. (1978). Journal use in sociology: citation analysis versus readership patterns. Library Quarterly, 48 (3), 293-300.

31. Pierce, S. J. (1999). Boundary crossing in research literatures as a means of interdisciplinary information transfer. Journal of the American Society for Information Science, 50 (3), 271-279.

32. Peritz, B. C. (1983). Are methodological papers more cited than theoretical or empirical ones? the case of sociology. Scientometrics, 5 (4), 211-218.

33. Smalley, T. N. (1981/1982). Trends in sociology literature and research: a comparison of characteristics of journal articles, 1968 and 1978. Behavioral \& Social Sciences Librarian, 2 (2/3), 1-19.

34. Lin, N., \& Nelson, C. E. (1969). Bibliographic reference patterns in core sociological journals, 1965-1966. American Sociologist, 4 (1), 47-50.

35. Cronin, B., Snyder, H., \& Atkins, H. (1997). Comparative citation rankings of authors in monographic and journal literature: a study of sociology. Journal of Documentation, 53 (3), 263-273. (p. 263) 
36. Davenport, E., \& Snyder, H. (1995). Who cites women? whom do women cite? an exploration of gender and scholarly citation in sociology. Journal of Documentation, 51 (4), 404-410.

37. Nock, D. A. (2001). Careers in print: Canadian sociological books and their wider impact, 1975-1992. Canadian Journal of Sociology, 26 (3), 469-486.

38. Ward, K. B., Gast, J., \& Grant, L. (1992). Visibility and dissemination of women's and men's sociological scholarship. Social Problems, 39 (3), 291-298.

39. Pierce, S. J. (1992). On the origin and meaning of bibliometric indicators: journals in the social sciences, 1886-1985. Journal of the American Society for Information Science, 43 (7), 477-487.

40. Oromaner, M. (1977). The diffusion of core publications in American sociology. Journal of the American Society for Information Science, 28 (1), 34-37.

41. Bott, D. M., \& Hargens, L. L. (1991). Are sociologists' publications uncited? citation rates of journal articles, chapters, and books. American Sociologist, 22 (2), 147-158. (p. 147)

42. Cronin, B., McKenzie, G., Rubio, L., \& Weaver-Wozniak, S. (1993). Accounting for influence: acknowledgments in contemporary sociology. Journal of the American Society for Information Science, 44 (7), 406-412.

43. Institute for Scientific Information. (1998). Journal citation reports, social sciences edition. Philadelphia, PA: Institute for Scientific Information. Retrieved April 11, 2003, from http://isi0.isiknowledge.com/portal.cgi. 
44. Institute for Scientific Information. (1999). Journal citation reports, social sciences edition. Philadelphia, PA: Institute for Scientific Information. Retrieved April 11, 2003, from http://isi0.isiknowledge.com/portal.cgi.

45. Institute for Scientific Information. (2000). Journal citation reports, social sciences edition. Philadelphia, PA: Institute for Scientific Information. Retrieved April 11, 2003, from http://isi0.isiknowledge.com/portal.cgi.

46. Institute for Scientific Information. (2001). Journal citation reports, social sciences edition. Philadelphia, PA: Institute for Scientific Information. Retrieved April 11, 2003, from http://isi0.isiknowledge.com/portal.cgi.

47. OCLC. (1992-2003). WorldCat. Library of Congress. Online. Retrieved May 7, 2003 from http://newfirstsearch.oclc.org/.

48. Library of Congress. (2002) Library of Congress Classification Outline. Online. Library of Congress, Cataloging Policy and Support Office. Retrieved May 7 , 2003 from http://www.loc.gov/catdir/cpso/lcco/lcco.html.

49. Ball, C. N., \& Connor-Litton, J. (1996-2003). Web Chi Square Calculator. Georgetown Linguistics. Online. http://www.georgetown.edu/faculty/ballc/webtools/web_chi.html.

50. American Sociological Association. (December 4, 2001). Distribution of faculty in graduate departments of sociology by rank and gender of faculty member (in percents), 1997-1998 academic year. Online. American Sociological Association. Retrieved May 9, 2003 from http://www.asanet.org/members/faculty1.html. 